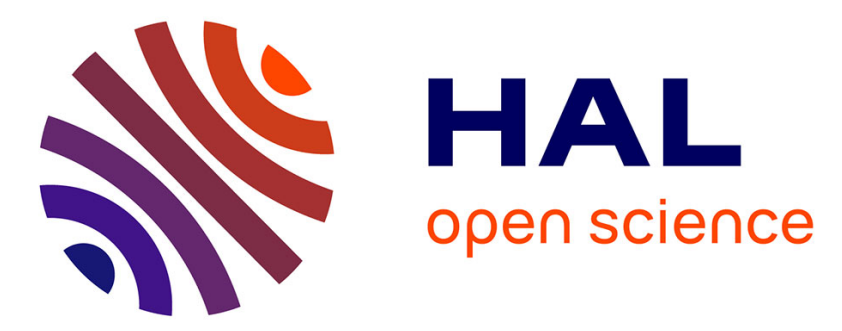

\title{
Unveiling the Residual Stresses, Local Micromechanical Properties and Crystallographic Texture in a Ti-6Al-4V Weld Joint
}

\author{
B. Mehdi, R. Badji, V. Ji, B. Alili, D. Bradai, W. Bedjaoui, Frédéric
}

Deschaux-Beaume, F. Brisset

\section{To cite this version:}

B. Mehdi, R. Badji, V. Ji, B. Alili, D. Bradai, et al.. Unveiling the Residual Stresses, Local Micromechanical Properties and Crystallographic Texture in a Ti-6Al-4V Weld Joint. Acta Metallurgica Sinica, 2021, 34 (7), pp.997-1006. 10.1007/s40195-020-01183-0 . hal-03344178

\author{
HAL Id: hal-03344178 \\ https://hal.science/hal-03344178
}

Submitted on 14 Sep 2021

HAL is a multi-disciplinary open access archive for the deposit and dissemination of scientific research documents, whether they are published or not. The documents may come from teaching and research institutions in France or abroad, or from public or private research centers.
L'archive ouverte pluridisciplinaire HAL, est destinée au dépôt et à la diffusion de documents scientifiques de niveau recherche, publiés ou non, émanant des établissements d'enseignement et de recherche français ou étrangers, des laboratoires publics ou privés. 


\title{
Unveiling the Residual Stresses, Local Micromechanical Properties and Crystallographic Texture in a Ti-6Al-4V Weld Joint
}

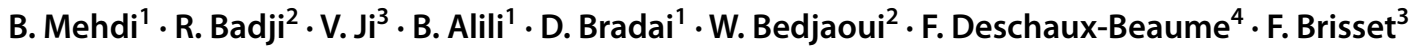

\begin{abstract}
In this work, the micromechanical properties, crystallographic texture, welding residual stresses and their evolution after plastic strain were investigated in a Ti-6Al-4 V alloy tungsten inert gas weld joint. It was found that the welding process affected the Young modulus and microhardness values in both $\alpha$ and $\beta$ phases in the different regions of the weld joint. The highest microhardness and Young modulus values of $\alpha$ phase were recorded in the heat-affected zone, whereas the highest values of these characteristics for the $\beta$ phase were found in the fusion zone (FZ). The change in the micromechanical properties was accompanied by a change in the crystallographic texture components of the dominant $\alpha$ phase from $(0001)<10-10>$ and $(11-20)<10-10>$ components in the base material to $(10-10)<11-20>$ and $(11-20)<3-302>$ components in the FZ. The introduction of tensile testing resulted in a continuous stress relaxation and improved the weld joint performances.
\end{abstract}

Keywords Ti-6Al-4 V · Tungsten inert gas (TIG) weld $\cdot$ Residual stress $\cdot$ Local mechanical properties $\cdot$ Crystallographic texture

\section{Introduction}

Due to the combination of high strength [1], low density [2] and excellent corrosion resistance [3], titanium alloys are used in many industrial applications such as aeronautics. The intensive use of these alloys requires the control of a panel of properties that can be changed by manufacturing and joining processes. Short et al. [4] considered the tungsten inert gas (TIG) welding as an economical fabrication process because of its low running cost, simplicity and possibility to perform

B. Mehdi

m_mehdi76@yahoo.fr

1 Laboratoire de Physique Des Matériaux, Facul té de Physique, Université Des Sciences Et de La Technologie Houari Boumediene, El-Alia, Bab-Ezzouar, B.P. 32, 16111 Alger, Algérie

2 Research Center in Industrial Technologies CRTI, P.O. Box64, Cheraga, Algeria

3 ICMMO/SP2M, Université Paris-Saclay, 91405 Orsay Cedex, France

4 LMGC, University of Montpellier, CNRS, Montpellier, France semi-automated welding operations. TIG welding is known to be the most common method used in titanium for industrial applications due to its comparatively easy and transportable facility [5].The mechanical properties of titanium welds are affected by the change in their microstructure/crystallographic texture [6] owing to complex phase transformations that may occur, particularly, in the fusion zone (FZ) [7]. The effect of pulse frequency on microstructure and mechanical properties of titanium alloys TIG welds has been well investigated [8]. The microstructure, mechanical properties and residual stresses in electron beam welded titanium alloy sheet were also investigated. It has been concluded that a complete martensitic transformation was not observed in the FZ at any of the welding current and a maximum of residual stresses were found in the longitudinal direction near the weld centerline [9]. It has also been concluded that the microstructural heterogeneity and the local stress concentration are the main reasons for the loss of ductility and premature fracture of the weld joint [6]. Balasubramanian et al. [10] evidenced that the use of pulsed TIG process decreased the prior $\beta$-grain size in the FZ of Ti-6Al-4 V weld joint and improved its mechanical properties. Junaid et al. [8] investigated the global mechanical behavior of Ti-6Al-4 V TIG welds through tensile testing and noticed that current pulsing improved the tensile strength of such weld joints. In order to estimate the sustainability 
of Ti-6Al-4 V weld joints, the local mechanical properties should be known accurately. In this context, a deep analysis of the local mechanical properties of the weld joint, in relation to its microstructural evolution, constitutes an important step for the development of TIG welds for aeronautic applications. Cai et al. [11] determined the mechanical properties of Ti-6Al-4 V alloy after heat treatment by nanoindentation measurements. They concluded that both microhardness and Young modulus were affected by the loading speed. The nanoindentation test has been also used to establish the correlation between micromechanical behavior and the different morphologies of $\alpha$ phase [12]. It has been noticed that the change in the Young modulus of the Ti-6Al-4 V alloy was principally caused by the contribution of the dislocation accumulation [12]. The $\alpha$ phase morphology and its amount strongly affect the Young's modulus in the Ti-6Al-4 V alloy [13]. For this reason, nanoindentation technique is the most suitable method to study the local mechanical properties of such alloys. The literature reports some studies dealing with the microstructure/crystallographic texture evolution in Ti-6Al-4 V weld joints. The welding heat input was controlled to adjust the microstructure and microtexture of $\mathrm{Cp}-\mathrm{Ti}$ and $\mathrm{Ti}-6 \mathrm{Al}-4 \mathrm{~V}$ inter-pulse gas tungsten arc welding [14]. Wu et al. [15] investigated the substructure of isothermal hot compression of TA15 alloy through electron backscattered diffraction (EBSD). Antonysamy et al. [16] reconstructed the primary $\beta$-phase from $\alpha$-phase in Ti-6Al-4 V alloy joined by selective electron beam welds. In this context, EBSD was adopted as a powerful tool to analyze the local microstructure and crystallographic texture and to highlight their relationship with the mechanical properties [17]. Fall et al. [17] concluded that the proportion of highangle grain boundary (HAGB) has an important influence on the impact toughness of Ti-6Al-4 V welds obtained by K-TIG welding. Despite the research works available in the literature, information concerning the correlation of the local mechanical properties of Ti-6Al-4 V TIG welds to their microstructure and microtexture is scare. Thus, this work aims at investigating the local micromechanical behavior of Ti-6Al-4 V TIG welds using indentation testing. The local micromechanical properties of each region of the weld joint [base material (BM), heataffected zone (HAZ) and fusion zone (FZ)] were determined in $\alpha$ phase and correlated to the corresponding microstructure/ crystallographic texture. The residual stress state in $\alpha$ phase was also investigated before and after interrupted tensile test.

\section{Experimental}

The base material used in this study is a Ti-6Al-4 V titaniumbased alloy received in a form of 1-mm-thickness sheet. Its chemical composition is given in Table 1. Automated pulsed TIG weld joints were realized under pure argon gas protection shielding (Fig. 1a) without filler material as shown in Fig. 1b.
The main conditions used for the joining process are given in Table 2. The welding direction was parallel to the rolling direction of the sheet. The microstructure and crystallographic textures in $\alpha$ phase were investigated using EBSD on a FEG-SEM SUPRA $55 \mathrm{VP}$ operating at $20 \mathrm{kV}$. Cross sections were prepared from the weld joint using standard technique of mechanical polishing and finishing by OPS suspension in a vibrometer apparatus. The data were collected by means of TSL orientation imaging microscopy $\left(\mathrm{OIM}^{\mathrm{TM}}\right)$ software. Quantitative texture analysis in $\alpha$ phase was carried out by calculating the pole figures using MTex software following the same methodology published elsewhere [18]. The optical microscopy characterization was performed using a Nikon Eclipse LV 100ND light optical microscope. For the nanoindentation measurements, a load of $10 \mathrm{mN}$ was employed to deduce the $P-h$ curve (load-displacement curve). An Anton-Paar TTXNHT3 nanoindenter equipped with a diamond Berkovich indenter type was used to determine the Young modulus and microhardness of each zone of the weld joint. The phase identification and residual stresses measurements were conducted using a Bruker D8 Discover X-ray diffractometer operating at $45 \mathrm{kV}, 40 \mathrm{~mA}$ with $\mathrm{Cu}-K$ radiation. The stress measurements in $\alpha$ phase were conducted according to the European standard NF EN [19] already cited in [20]. To define the correct mechanical adjustment, a standard Ti-6Al-4 V specimen was used to calibrate the equipment. The used parameters for stress analysis are listed in Table 3. The residual stresses in $\alpha$ phase were evaluated on a specimen containing the different regions of the weld joint (BM, HAZ and FZ) at the welded state and after tensile testing. To this end, tensile specimens were taken perpendicularly to the welding direction and machined according to the ASTM E8/EM-09 standard [21]. Interrupted tensile tests were conducted at a constant strain rate of $10^{-4} \mathrm{~s}^{-1}$ for 1.5, 2.5 and 5.2\% macroscopic strains using an MTS tensile testing machine.

\section{Results}

\subsection{Qualitative Phase Identification by X-ray Diffraction (XRD)}

Figure 2 shows the XRD patterns recorded in different regions (BM, HAZ and FZ) of the investigated Ti-6Al-4 V TIG weld. The XRD pattern of the BM reveals the presence of typical $\alpha$ and $\beta$ phases. The relative peak intensity evolution from the BM to the FZ through the HAZ of $\alpha$

Table 1 Chemical composition of the studied Ti-6Al-4 V alloy

\begin{tabular}{lllll}
\hline Element & $\mathrm{Al}$ & $\mathrm{Ti}$ & $\mathrm{V}$ & $\mathrm{Fe}$ \\
\hline (wt\%) & 5.65 & 90.25 & 3.85 & 0.25 \\
(at.\%) & 14.84 & 81.82 & 3.08 & 0.26 \\
\hline
\end{tabular}



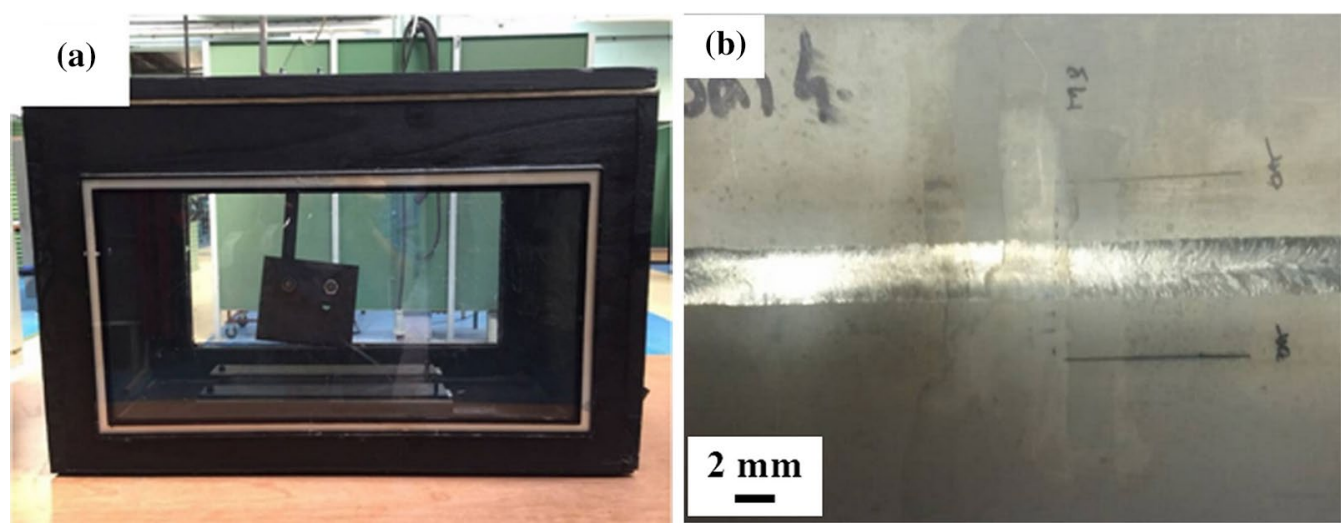

Fig. 1 a Vacuum chamber used for the Ti-6Al-4 V TIG welding, b specimen of the welded sheets

Table 2 Used welding parameters

\begin{tabular}{|c|c|c|c|c|c|c|c|c|c|}
\hline $\begin{array}{l}\text { Electrode } \\
\text { diameter }\end{array}$ & $\begin{array}{l}\text { Sharpening } \\
\text { angle }\end{array}$ & $\begin{array}{l}\text { Argon gas } \\
\text { flow }\end{array}$ & $\begin{array}{l}\text { Pulsed } \\
\text { current fre- } \\
\text { quency }\end{array}$ & Arc height & $\begin{array}{l}\text { Pulse time/ } \\
\text { background } \\
\text { time }\end{array}$ & Pulse current & $\begin{array}{l}\text { Background } \\
\text { current }\end{array}$ & $\begin{array}{l}\text { Welding } \\
\text { speed }\end{array}$ & Voltage \\
\hline $2.5 \mathrm{~mm}$ & 35 & $121 / \mathrm{min}$ & $6 \mathrm{~Hz}$ & $2.8 \mathrm{~mm}$ & $50 / 50$ & $100 \mathrm{~A}$ & $50 \mathrm{~A}$ & $10 \mathrm{~cm} / \mathrm{min}$ & $\sim 10 \mathrm{~V}$ \\
\hline
\end{tabular}

Table 3 Residual stress measurement parameters

\begin{tabular}{ll}
\hline Parameters & Values \\
\hline$\Psi$ angles: $28^{\circ}$ (by step of $\left.5^{\circ}\right)$ & -70 to $+70^{\circ}$ \\
Atomic plane for deformation $\left(\varepsilon_{\phi \psi}\right)$ measurements & $(21-33)$ \\
Diffraction angle for the associate peak & $2 \theta=142^{\circ}$ \\
Elastic constants of the studied material & Young modu- \\
& lus: $E=120$ \\
& GPa \\
& Poisson \\
Anisotropic factor $A_{\mathrm{RX}}$ & coefficient: \\
Stress analysis precision & $\nu=0.33$ \\
\hline
\end{tabular}

and $\beta$ phases is clearly revealed in the figure. In the $\mathrm{FZ}$, the (10-11) $\alpha$ and (11-20) $\alpha$ peak intensities increased significantly and those of $(11-10)_{\alpha}$ and $(0002)_{\alpha}$ ones decreased markedly. Other peaks associated with $\alpha$ phase experienced a slight change in their relative intensities. This result may be explained by the change in crystallographic texture that will be discussed in Sect. 3.4. The relative intensities of the $(110)_{\beta}$ and $(200)_{\beta}$ peaks associated with the $\beta$ phase observed in the BM were slightly reduced in the HAZ. In the FZ, a total disappearance of the $(200)_{\beta}$ peak and a strong decrease in the intensity of the $(110)_{\beta}$ peak were evidenced. The presence of a high amount of $\alpha$ phase in the FZ is the result of the $\beta$ to $\alpha$ phase transformation during the welding process and the formation of the lamellar and martensitic

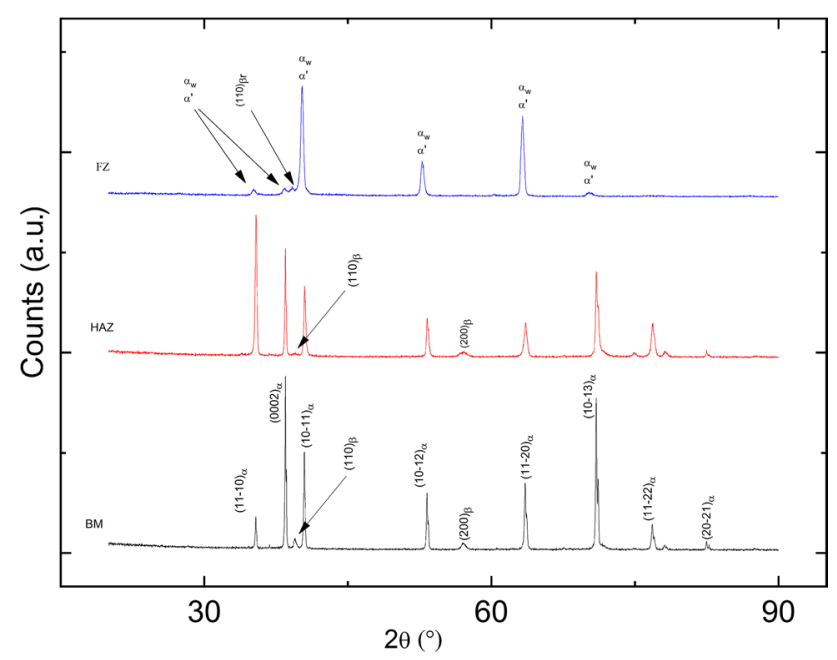

Fig. 2 X-ray patterns of the different zones of Ti-6Al-4 V TIG weld

morphologies as already observed by Kamlesh et al. [22]. These authors have assessed through XRD spectra, and the percentage of $\alpha$ and $\beta$ phases were 92.5 and 5.5\%, respectively, for different welding currents that are close to those of the present study. However, the scan speed used in the present study was somewhat higher ( $~ 5$ times). They evidenced a net increase in the $\beta$ phase fraction upon increasing scan speed. Therefore, one can speculate that it should be more than $7.3 \%$. It should be noted that the $(110)_{\beta}$ peak 
with a weak intensity observed in the FZ is ascribed to the retained $\beta$ after solidification.

\subsection{Local Micromechanical Properties in the Different Regions of the Weld Joint}

The microhardness $\left(\mathrm{HV}_{0.3}\right)$ evolution across the Ti-6Al-4 V TIG weld joint is shown in Fig. 3. An improvement of about $15 \%$ is observed in the hardness of the HAZ in comparison to the BM, whereas only $10 \%$ of improvement can be depicted in the hardness of the FZ comparatively to the HAZ. This result could be attributed to the effect of the developed $\alpha$ phase morphology in the FZ after the $\beta$ to $\alpha$ phase transformation. The $\alpha$ phase in the FZ generally exhibits acicular and lamellar morphologies after TIG welding process. Consequently, the density of the $\alpha / \beta$ interfaces increases considerably refining the overall grain size and then leading to microhardness improvement of this region according to the Hall-Petch strengthening [23].

In order to highlight the role of $\alpha$ and $\beta$ phases in the local mechanical properties of each zone, nanoindentation measurements were conducted. Figure 4 shows an optical image of indentation fingerprints made in the fusion zone. The obtained values were an average of 49 indentations realized in a frame of $7 \times 7$ matrix points in the same zone. Consequently, a maximum number of points associated with $\alpha$ and $\beta$ phases, further analyzed through XRD, was indented. An example of the corresponding $(P-h)$ curves determined in these zones is illustrated in Fig. 5. After a statistical analysis, two different mean values of the Young modulus and microhardness associated to $\alpha$ and $\beta$ phases were determined as shown in Fig. 6 a, b. The obtained values are also consigned in Table 4. It is clear that the collected

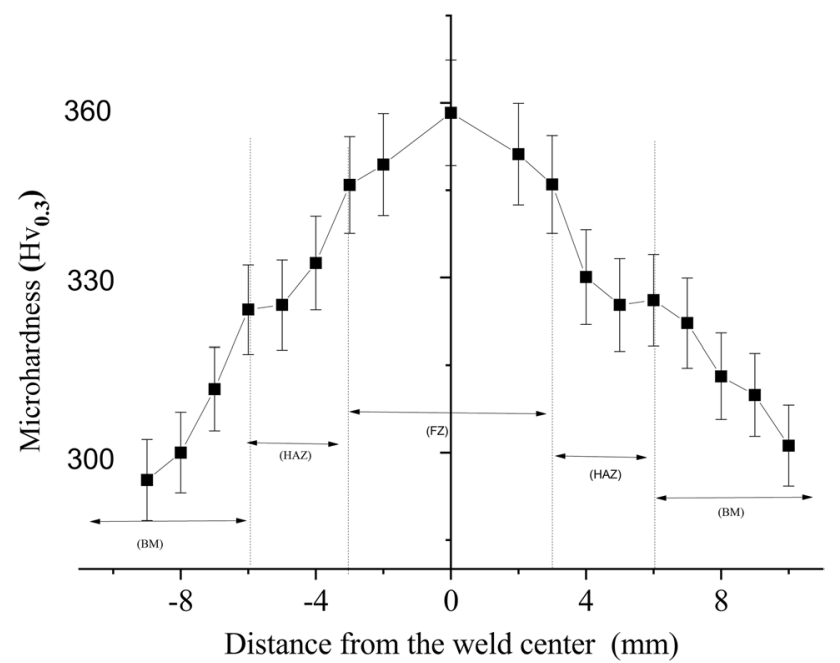

Fig. 3 Evolution of the microhardness $\mathrm{HV}_{0.3}$ in the different regions of Ti-6Al-4 V TIG weld

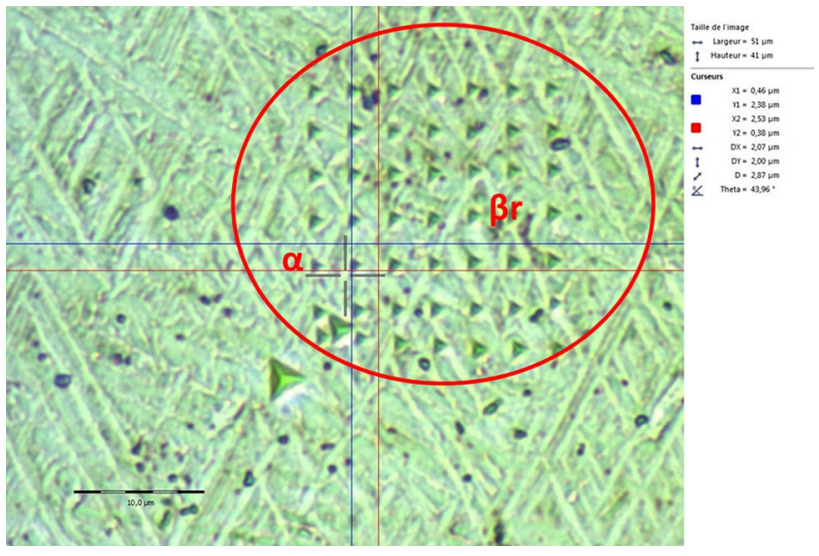

Fig. 4 Optical image of indentations obtained in the FZ

values from the indentation tests are not the same for the different weld zones in both $\alpha$ and $\beta$ phases. Considering the dominant $\alpha$ phase, the Young modulus and microhardness are slightly higher in the FZ than in the BM and even higher in the HAZ. The Young modulus and the microhardness of the $\alpha$-phase are about $30 \%$ higher than those of the $\beta$ phase for the different regions of the weld joint. This result is in a good agreement with those published by Lee et al. [24]. These authors assumed that interstitial and substitutional $\alpha$-stabilizing solutes (like $\mathrm{Al}$ ) improve the Young modulus, whereas $\beta$-stabilizing ones (like $\mathrm{V}$ ) decrease it in Ti-6Al-4 V. Leyens and Peters [25] also supported that the microstructure of Ti-6Al-4 V alloy is strongly dependent on its chemical composition. Therefore, the obtained results could reasonably be attributed to the difference in the chemical composition of $\alpha$ and $\beta$ phases in the different weld regions. Increasing the volume fraction of the $\beta$ phase

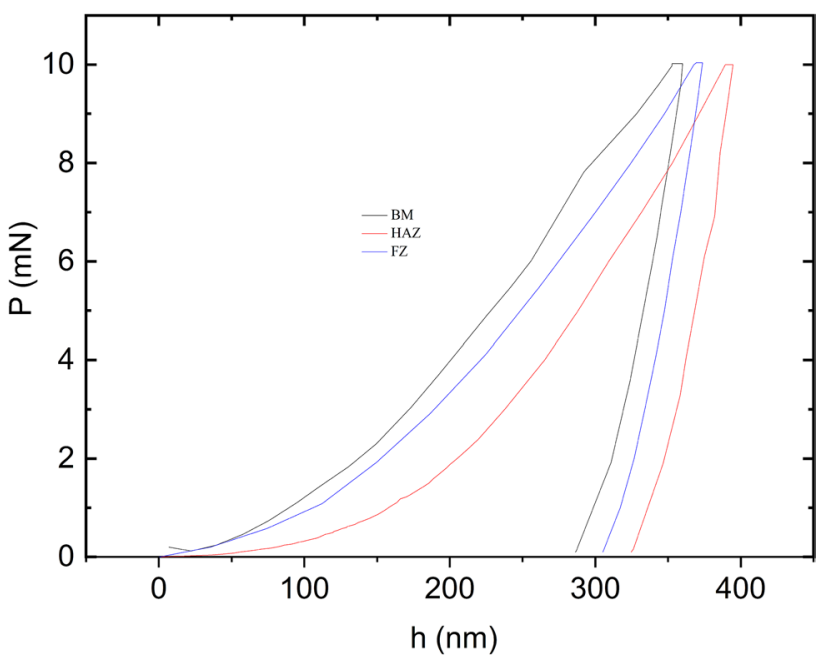

Fig. $5 P-h$ curves of $\alpha$ phase in the different weld zones Ti-6Al-4 V TIG weld 

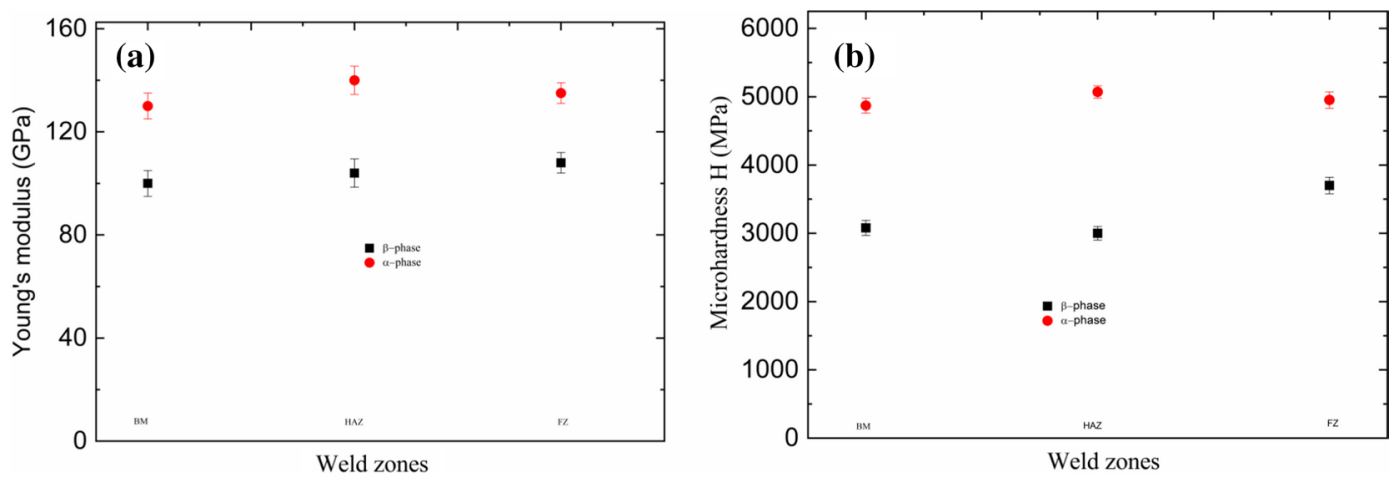

Fig. 6 Evolution of: a Young's modulus and $\mathbf{b}$ microhardness of the $\alpha$ and $\beta$ phases in the different weld zones

Table 4 Micromechanical properties in the different regions of the investigated $\mathrm{Ti}-6 \mathrm{Al}-4 \mathrm{~V}$ weld joint obtained from nanoindentation measurements

\begin{tabular}{lllll}
\hline Weld zones & $\begin{array}{l}\text { Young's } \\
\text { modulus, } E_{\beta} \\
(\mathrm{GPa})\end{array}$ & $\begin{array}{l}\text { Microhard- } \\
\text { ness, } H_{\beta} \\
(\mathrm{MPa})\end{array}$ & $\begin{array}{l}\text { Young's } \\
\text { modulus, } E_{\alpha} \\
(\mathrm{GPa})\end{array}$ & $\begin{array}{l}\text { Micro- } \\
\text { hardness, } \\
H_{\alpha}(\mathrm{MPa})\end{array}$ \\
\hline $\mathrm{BM}$ & $100 \pm 0.9$ & $3500 \pm 110$ & $125 \pm 0.9$ & $4840 \pm 110$ \\
$\mathrm{HAZ}$ & $104 \pm 1.2$ & $3000 \pm 90$ & $140 \pm 1.2$ & $5080 \pm 90$ \\
$\mathrm{FZ}$ & $108 \pm 1.6$ & $3600 \pm 120$ & $135 \pm 1.6$ & $4952 \pm 120$ \\
\hline
\end{tabular}

in the microstructure of $\mathrm{Ti}-6 \mathrm{Al}-4 \mathrm{~V}$ alloy reduces the elastic modulus and the hardness as stated by Zhang et al. [26].

\subsection{Effect of Interrupted Tensile Testing on the Welding Residual Stresses Evolution}

Figure 7 shows the evolution of the longitudinal $\left(\sigma_{L}\right)$ and transversal $\left(\sigma_{T}\right)$ residual stresses in $\alpha$ phase, at the aswelded state, measured using X-ray diffraction. Both $\sigma_{L}$ and $\sigma_{T}$ stresses exhibit symmetric profile. The $\sigma_{L}$ stresses in the $\mathrm{BM}$ are of compressive type with a mean value of $-160 \mathrm{MPa}$. The $\sigma_{L}$ of the HAZ are of tensile type with a mean value close to $+160 \mathrm{MPa}$. Weak compressive $\sigma_{L}$ with a mean value of $-50 \mathrm{MPa}$ were recorded in the FZ. It is also clear from Fig. 7 that the $\sigma_{T}$ values are lower than those of $\sigma_{L}$. This result can be explained by the nature of the TIG welding process that did not strongly affect the welded sheet in the transversal direction [20]. In order to examine the effect of plastic strain on the as-welded longitudinal residual stresses $\sigma_{L}$, interrupted tensile tests were conducted on the welded specimens at different macroscopic strain percentages in the plastic domain. The tensile behavior of the welded specimens is governed by both welding residual stresses and local micromechanical properties of the different regions of the weld joint. The obtained results are shown in Fig. 8a. The actual $\sigma_{L}$ values

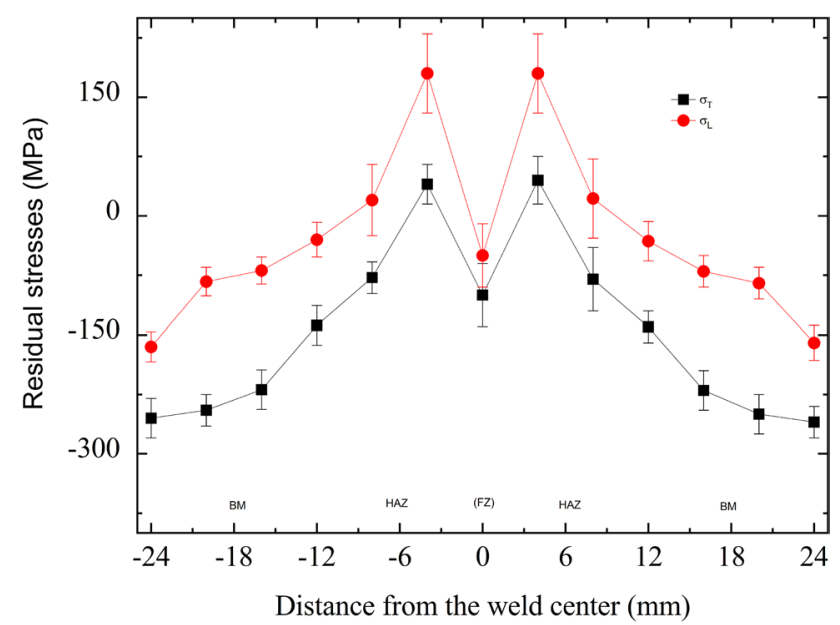

Fig. 7 Longitudinal $\left(\sigma_{L}\right)$ and transversal $\left(\sigma_{T}\right)$ welding residual stress in the different regions of the Ti-6Al-4 V TIG weld

in $\alpha$ phase of each region of the weld joint (BM, HAZ and FZ) are revealed in Fig. 8b. It is clearly observed that the $\sigma_{L}$ level (magnitude) in $\alpha$ phase decreased in the BM and FZ after $1.5 \%$ macroscopic strain. The values of $\sigma_{L}$ in the HAZ decreased slightly after $1.5 \%$ macroscopic strain. The $\sigma_{L}$ values in $\alpha$ phase decreased more sensibly in the HAZ, the $\mathrm{BM}$ and $\mathrm{FZ}$ when increasing the macroscopic deformation up to $2.5 \%$. In the last stage of the plastic deformation (up to 5.2\%), the longitudinal residual stresses in $\alpha$ phase stabilized at $(+10 \mathrm{MPa}),(-60 \mathrm{MPa})$ and $(+70 \mathrm{MPa})$ for FZ, BM and HAZ, respectively. It should be noted that the RSs in the HAZ remained the tensile type until the end of the deformation process. These results predict quite high performance of the realized weld joints and suggest that the control of the mechanical behavior of the investigated Ti-6Al-4 V TIG welds can be achieved through interrupted tensile testing in order to relax the welding residual stresses. 

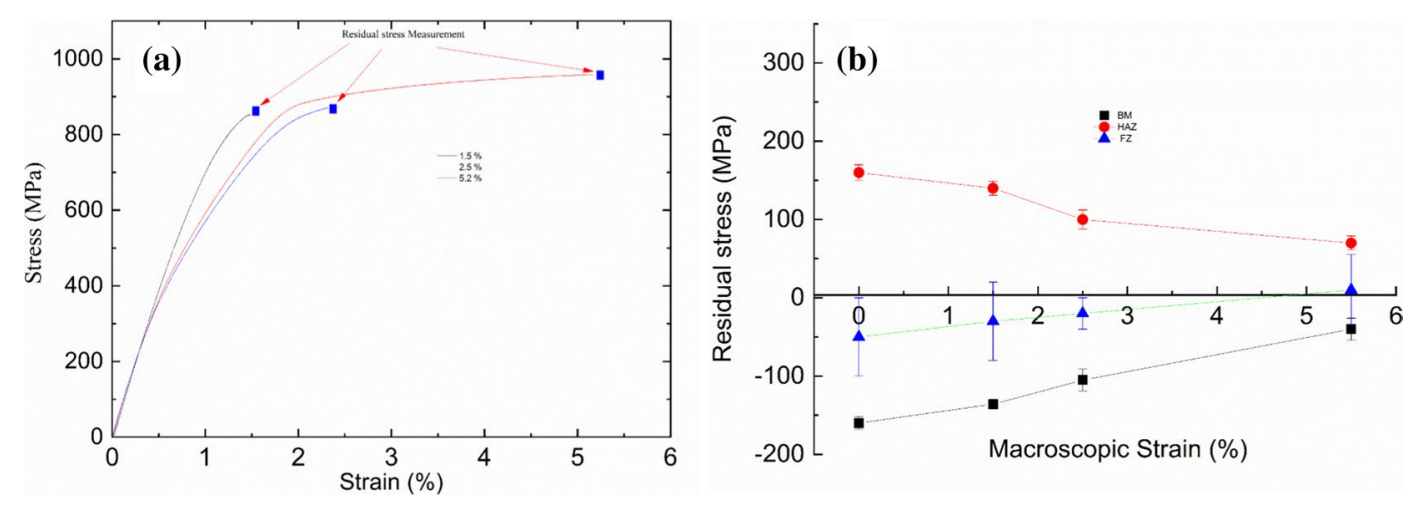

Fig. 8 a Tensile curves obtained during interrupted tensile tests, b mean residual stress evolution in the different weld zones after interrupted tensile tests

\subsection{Microstructure and Crystallographic Texture Evolution Across the Weld Joint}

The different regions of the Ti-6Al-4 V weld joint are illustrated in the macrograph shown in Fig. 9a. Figure 9b, c, d, e shows the EBSD orientation maps in $\alpha$ phase obtained in the different regions of the weld joint. The BM orientation map exhibits fine deformed grains that are elongated through the rolling direction of the sheet (Fig. 9b). Similar behavior can be observed in the transition BM/HAZ as identified in Fig. 9c. The HAZ microstructure is composed of $\alpha$ laths and $\alpha^{\prime}$ martensitic morphologies as shown in Fig. 9d. The observed phase morphology in this zone indicates that the temperature induced by the welding thermal cycle might exceed the $\beta$-transus temperature. The microstructure of the FZ (Fig. 9e) is characterized by large prior- $\beta$ grains, composed of $\alpha_{\mathrm{w}}$ Widmansttäten and martensitic $\alpha^{\prime}$ morphologies. The observed phase morphologies in the present study are in concordance with the typical microstructures obtained after TIG joining of titanium alloys $[2,14,27]$. Figure 10 shows the crystallographic texture evolution of the dominant $\alpha$ phase across the different regions of the weld joint in terms of (0001) $\alpha$ and (10-10) $\alpha$ recalculated pole figures. The ideal locations of the different identified texture components in this work are represented in Fig. 11. The crystallographic texture of the $\alpha$ phase in the $\mathrm{BM}$ and $\mathrm{BM} /$ HAZ regions showed an hexagonal $(0001)<10-10>$ component with intensities of 6.4 and $6.8 \mathrm{mrd}$ (multiple of random), respectively. The $\mathrm{BM} / \mathrm{HAZ}$ zone exhibited an additional weak hexagonal $(11-20)<10-10>$ component with an intensity of $1.5 \mathrm{mrd}$. This texture component was $90^{\circ}$ rotated away from the so-called transverse texture. Such typical deformation texture component was observed in titanium alloys during hot rolling [28]. Quite different crystallographic textures were observed in both HAZ and FZ. Indeed, the initial texture components described above totally vanished and a new $(10-10)<11-20>$ crystallographic texture component, with an intensity of $\sim 5.6 \mathrm{mrd}$, dominated the microstructure of the
HAZ. The FZ also contained a $(01-10)<11-20>$ texture component with relatively higher intensity $(\sim 10 \mathrm{mrd})$.

A $(11-20)<3-302>$ component with pole densities of 3.4 and 5.6 mrd was also identified in the HAZ and the FZ, respectively. The development of the $(11-20)<3-302>$ texture component was attributed to the occurrence of static recrystallization (SRX) [27].

The histograms of the grain boundary misorientation in $\alpha$ phase of the different regions of the Ti-6Al-4 V weld joint are shown in Fig. 12. It is clear that the different regions of the weld joint did not exhibit a random distribution. Apart from the presence of relatively great amount of low angle grain boundaries (LAGBs), no special feature could be depicted for the misorientation distribution in the BM and the BM/HAZ regions. This finding is clearly revealed in Fig. 13 which shows the distribution of LAGBs and highangle grain boundaries (HAGBs) in $\alpha$ phase. Quite different distributions are noticed for the HAZ and FZ where a profusion of misorientation near $60^{\circ}-63^{\circ}$ is observed. The misorientation corresponding to the boundaries between $\alpha$ phase colonies was inherited from the same parent $\beta$ grain [29]. The evolution of LAGB and HAGB fractions may plausibly be explained by the texture evolution across the different zones of the weld joint. Indeed, in the BM and BM/HAZ zones, most of $\alpha$ grains are more or less closely oriented around the typical $(0001)<10-10>$ and $(11-20)<10-10>$ orientations. In the HAZ and FZ, the formation of new grains with $(01-10)<11-20>$ and $(11-20)<3-302>$ orientations after the $\beta \rightarrow \alpha$ phase transformation may be accompanied by the creation of HAGBs.

\section{Discussion}

In this work, an approach is adopted to evaluate the performances of a Ti-6Al-4 V TIG weld joint through the determination of the local mechanical properties in its different 

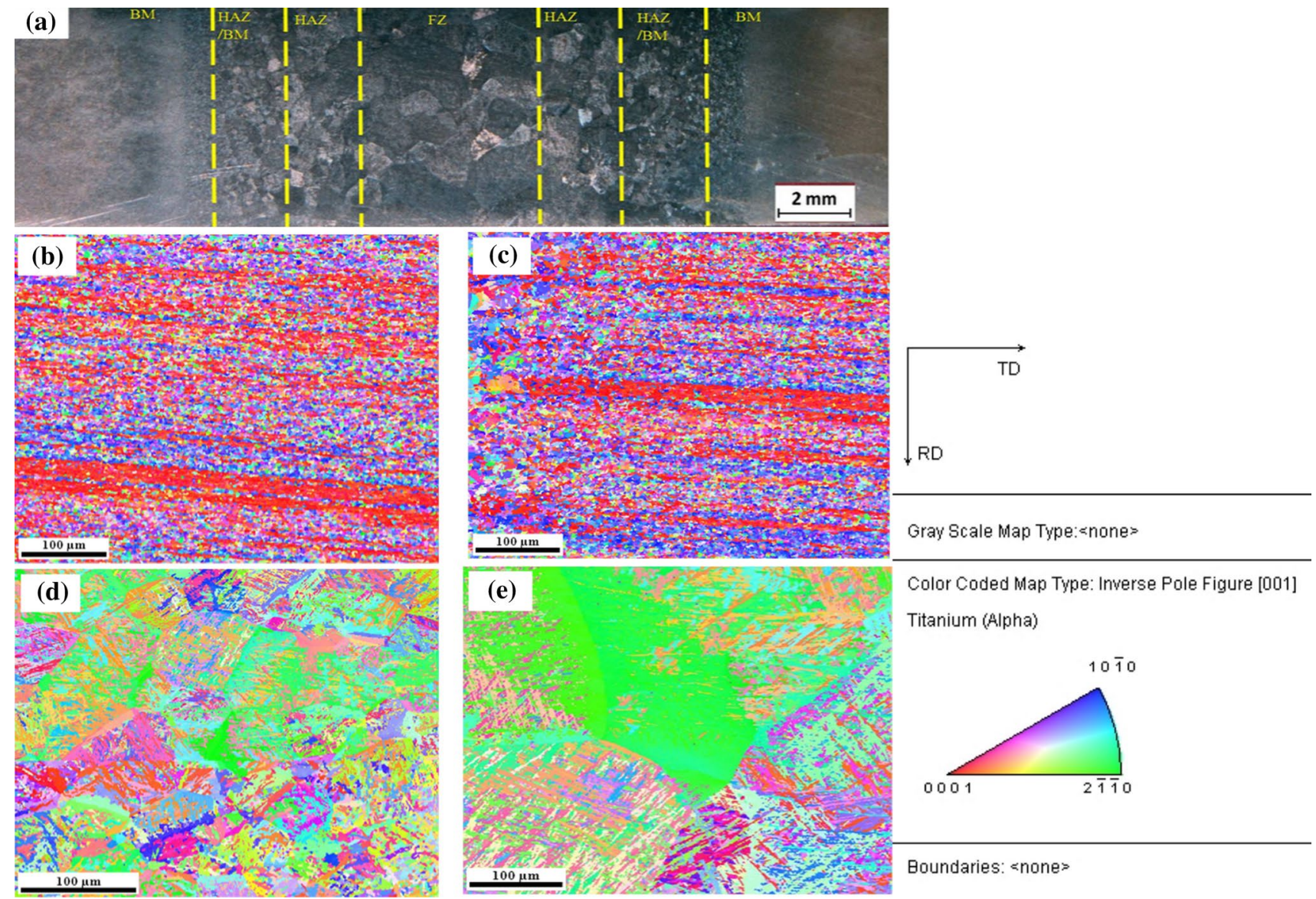

Color Coded Map Type: Inverse Pole Figure [001]

Titanium (Alpha)

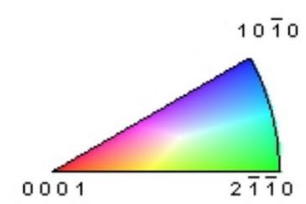

Boundaries: «none=

Fig. 9 a Macrographs of the welded sheet illustrated in different regions, b inverse pole figure (IPF) maps obtained for the BM, c IPF maps obtained for the BM/HAZ, d IPF maps obtained for the HAZ, e IPF maps obtained for the FZ

regions. The effect of the residual stress state in $\alpha$ phase on these local mechanical properties is considered. The longitudinal residual stress state in the $\alpha$ phase depicted after the welding process was affected by the change in the microstructure and crystallographic texture. Consequently, the local mechanical properties changed in both $\alpha$ and $\beta$ phases in the different regions of the weld joint. A low longitudinal residual stress level in $\alpha$ phase was recorded in the FZ comparatively to the BM and HAZ. The longitudinal residual stress value measured in the HAZ was higher (+160 MPa) in comparison to the BM and FZ. The decrease in the residual stress level in $\alpha$ phase resulted from the nature of the phase transformation that occurred during the welding process. This is in good agreement with the results published by Bikash et al. [30]. The estimated local mechanical properties in this work suggest that the elastic properties (Young modulus) and the hardness may significantly depend on the welding residual stress level. As stated in [24] and [25], the properties of the as-received alloy, its chemical composition (which influences the Young modulus value) and the transformation during cooling rate (TCR) conditions (which affects the microhardness state) are the main factors that influence the lattice parameter expansion during welding and that may generate tensile or compressive residual stresses [20].

The effect of base the material on microstructure and crystallographic orientation evolution of a Ti-6Al-4 V electron beam welded joint was investigated using EBSD [31]. These authors have confirmed that both grain morphology and crystallographic orientation of the electron beam welding joint would depend on the base material microstructure. From EBSD examination, the results revealed a significant change in the microstructure and crystallographic texture components of $\alpha$ phase in both the FZ and the HAZ compared to the BM. Indeed, the crystallographic texture of the $\mathrm{BM}$ in $\alpha$ phase was not retained at the end of the welding process. After the $\beta \rightarrow \alpha$ phase transformation, the pole figures of the HAZ and the FZ illustrated in Fig. 10 were characterized by a marked texture components compared to those of the BM. These sharp textures can also affect the local Young's modulus and microhardness and therefore explain the change of the local mechanical properties obtained in 

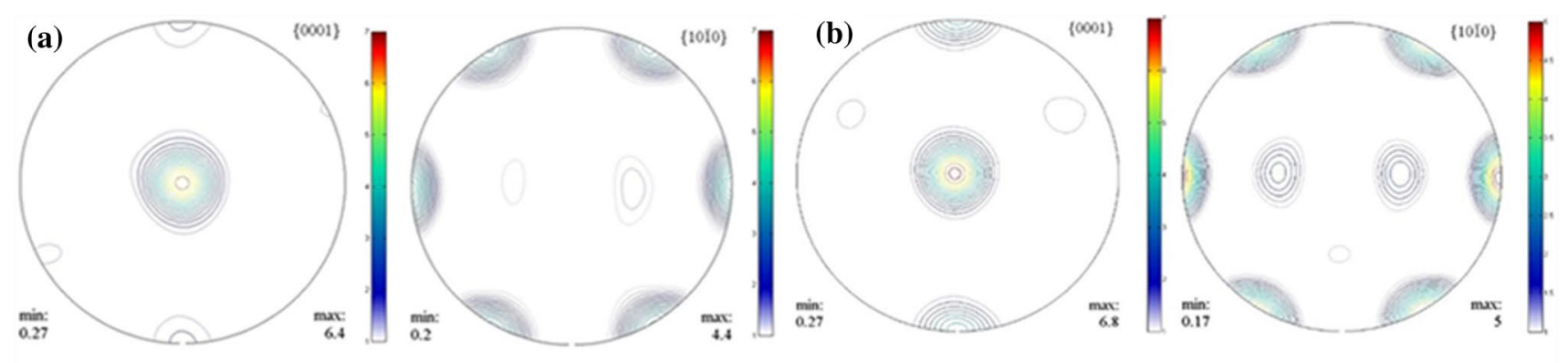

BM

BM/HAZ

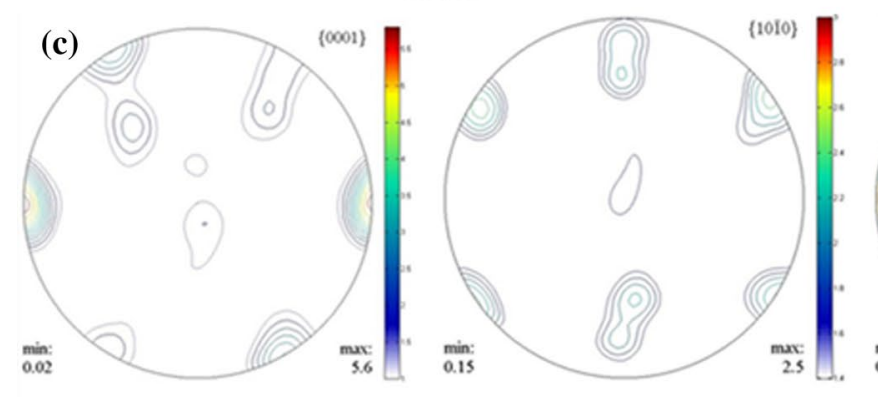

HAZ

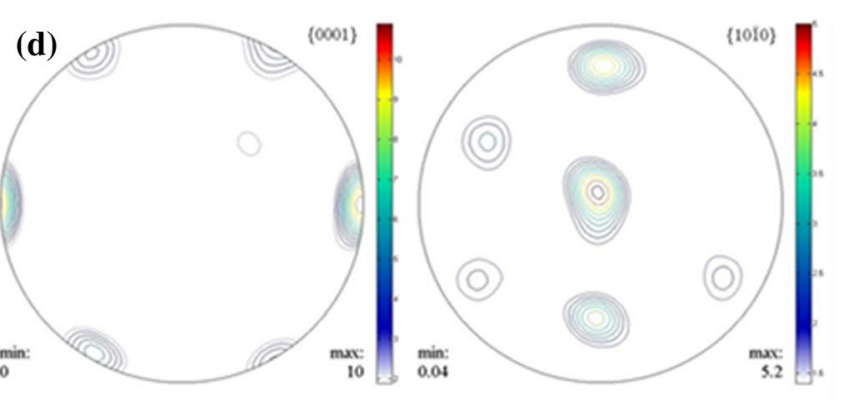

FZ

Fig. 10 Recalculated (0001) and (10-10) pole figures obtained from EBSD measurements in BM, BM/HAZ, HAZ and FZ zones

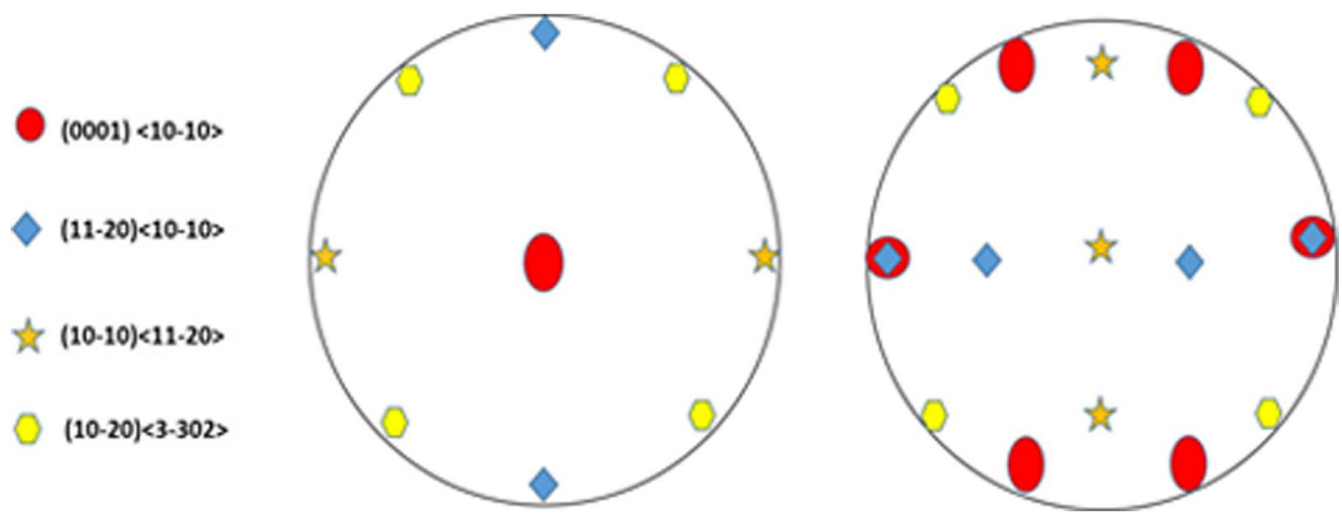

Fig. 11 Identified hexagonal texture components observed in the present study

this investigation across the different weld joint regions. A net change of the Young modulus values has been shown by Yi et al. [27] which is related to qualitative and quantitative aspects of the crystallographic texture components in the $\alpha$ phase. The Young modulus of $\alpha$ titanium changed considerably when the measurements were conducted between the $c$-axes of the unit cell and stress axis. The Young modulus varied between $145 \mathrm{GPa}$ (parallel to $c$-axis) and $100 \mathrm{GPa}$ (perpendicular to this axis) [4]. Moreover, the decrease in the Young modulus could be attributed to the micro-plasticity of isolated sub-grains [32]. Hiroaki et al. [33] attributed the decrease in the Young modulus in a Ti alloy to $\mathrm{Sn}$ addition which caused a lattice expansion in the martensitic phase. The Young modulus values in polycrystalline pure $\mathrm{Ti}$ changed accordingly with the preferred texture (basal texture) [24]. In this work, the HAZ experienced higher Young modulus compared to the BM and the FZ. This can be directly related to the apparition of a new texture component in the HAZ and FZ after the $\beta \rightarrow \alpha$ phase transformation. When the crystallographic texture changed, the Young modulus of the $\alpha$ phase varied from $125 \mathrm{GPa}$ in the $\mathrm{BM}$ to 135 $\mathrm{GPa}$ in the FZ then to $140 \mathrm{GPa}$ in the HAZ. Therefore, it can be deduced that the formation of $(11-20)<3-302>$ texture component observed above is the main reason for the change 


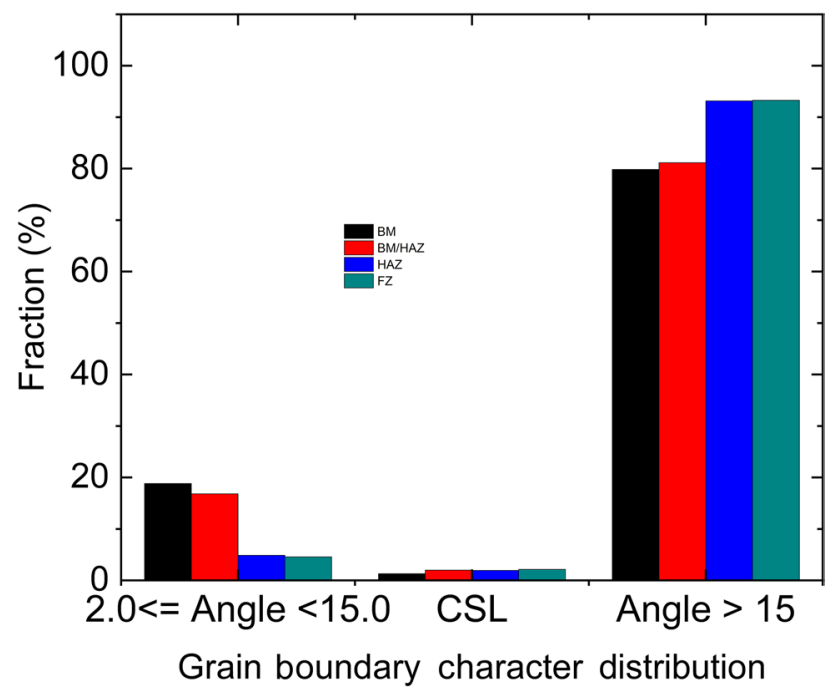

Fig. 12 Grain boundary character distribution in the BM, BM/HAZ, $\mathrm{HAZ}$ and $\mathrm{FZ}$ zones

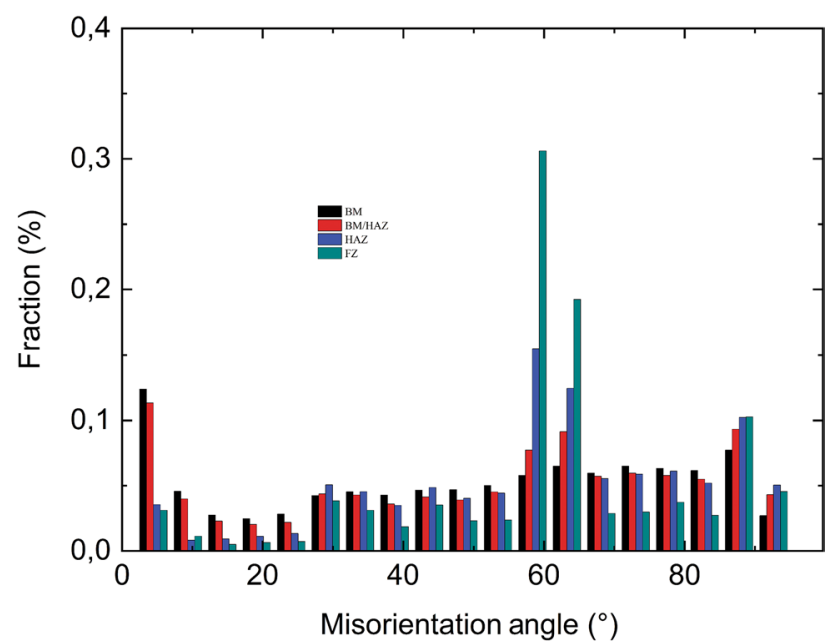

Fig. 13 Histogram of misorientation angle distribution in the BM, $\mathrm{BM} / \mathrm{HAZ}, \mathrm{HAZ}$ and FZ zones

in the Young's modulus value in the FZ. The HAZ exhibited high strength compared to the $\mathrm{FZ}$ and the $\mathrm{BM}$; this result was related to the presence of the $(10-10)<11-20>$ texture component in the $\alpha$ phase. The TIG welding process produced a random crystallographic texture; consequently, a decrease in the tensile strength of the weld joint was observed [34]. Bache [35] attributed the change of the yield strength in a Ti-6Al-V alloy to the anisotropy of its mechanical properties. In addition, the evolution of the local mechanical properties was attributed to activated slip systems in $\alpha$ phase after indentation loading. The methodology adopted in this work may describe the global mechanical behavior of the investigated Ti-6Al-4 V TIG welds. The high value of the welding longitudinal residual stress in $\alpha$ phase recorded in the
HAZ can be the origin of its hardness increase. In addition, Kamlesh et al. [22] concluded that a grain refinement of the microstructure after the welding process was accompanied by an increase in the residual stress level. The residual stress state obtained after interrupted tensile testing in $\alpha$ phase $(+70 \mathrm{MPa}$ in the $\mathrm{HAZ},+10 \mathrm{MPa}$ in the $\mathrm{FZ}$ and $-60 \mathrm{MPa}$ in the $\mathrm{BM}$ ) suggests that a plastic deformation took place, firstly in the HAZ. In addition to residual stresses, a local change in the microstructure and microtexture significantly influences the mechanical properties of titanium alloys weld joint [36]. The strengthening of Ti-6Al-4 V alloy may result from both transformation texture and prior $\beta$-grain size evolution. During plastic deformation, the differently oriented $\alpha_{\mathrm{w}}$ lamella would affect the dislocation activity within the microstructure. The dislocation mobility in the HAZ would be higher than those in the BM and the FZ [34].The internal stress evolution in $\alpha$ phase is strongly affected by the microstructure and crystallographic texture. The high interphase stress level was generated when the crystallographic texture and microstructure changed [37]. Therefore, in this study, a deformation incompatibility across the lamellar interfaces and grain boundaries is thought to occur in the HAZ. This deformation incompatibility suggests a quick tendency of this region towards damage. Based on the results obtained in this work, it can be suggested that the global mechanical behavior of the investigated Ti-6Al-4 V weld joint results from the contribution of the phases constituting the microstructure of each weld zone (BM, HAZ and FZ). The crystallographic texture throughout the Ti-6Al-4 V TIG weld does not only depend on the morphologies and orientation of $\alpha$ phase, and it depends also on the local mechanical properties of the different regions of the weld joint. These properties are influenced by the amount and the chemical composition of both $\alpha$ and $\beta$ phases in the Ti-6Al-4 V weld joint.

\section{Conclusions}

In this work, residual stress state, local micromechanical properties and crystallographic texture in a Ti-6Al-4 V TIG weld joint were examined. The main conclusions can be given as follows:

1. TIG welding of Ti-6Al-4 V alloy resulted in a significant change in the local micromechanical properties across the weld joint. The Young modulus and microhardness of $\alpha$ phase were higher than those of the $\beta$ phase in the different regions of the weld joint. The highest micromechanical values of $\alpha$ phase were recorded in the HAZ, whereas the highest micromechanical values of the $\beta$ phase were found in the FZ.

2. Tensile residual stresses were recorded in the HAZ, whereas weak compressive ones were obtained in the 
FZ. A gradual relaxation of these residual stresses, namely in the FZ, was recorded with the introduction and increase in the plastic deformation.

3. The crystallographic texture components of the dominant $\alpha$ phase changed from the FZ to the BM through the HAZ with respect to the change in the micromechanical properties caused by the welding process.

4. The obtained results highlighted the good performances of the realized weld joints and led to conclude that the residual stress relaxation in the investigated Ti-6Al-4 V TIG welds could be achieved through interrupted tensile testing.

Acknowledgements The authors wish to thank Dr. Y.I. Bourezg from Ziane Achour, University of Djelfa, Algeria, for his assistance. Prof. R. Annou from the University of Sciences and Technology Houari Boumediene USTHB, Algiers, Algeria, is hearty acknowledged for the manuscript improvement.

\section{References}

[1] J. Lin, N. Ma, X. Liu, Y. Lei, J. Mater. Process. Technol. 278, $116504(2020)$

[2] S. Cui, Y. Shi, T. Zhu, W. Lei, J. Manuf. Proc. 37, 418 (2019)

[3] T. Sun, Y. Liu, S.J. Li, J.P. Li, Acta Metall. Sin. -Engl. Lett. 32, 869 (2019)

[4] A.B. Short, Mater. Sci. Technol. 25, 309 (2009)

[5] Z.B. Wang, H.X. Hu, C.B. Liu, H.N. Chen, Y.G. Zheng, Acta Metall. Sin. -Engl. Lett. 28, 477 (2015)

[6] M.R. Bache, Int. J. Fatigue 25, 1079 (2003)

[7] X.L. Gao, L.J. Zhang, J. Liu, Z.J.X. Zhang, Mater. Sci. Eng. A 559, 14 (2013)

[8] M. Junaid, M.N. Baig, M. Shamir, F.N. Khan, K. Rehman, J. Haide, J. Mater. Process. Technol. 242, 24 (2017)

[9] M. Junaid, F.N. Khan, N. Bakhsh, M.N. Baig, K. Rahman, Mater. Des. 139, 198 (2018)

[10] T.S. Balasubramanian, V. Balasubramanian, M.A. Muthumanickam, Mater. Des. 32, 4509 (2011)
[11] J. Cai, F. Li, T. Liu, B. Chen, Mater. Charact. 62, 287 (2011)

[12] J. Dong, F. Li, C. Wang, Mater. Sci. Eng. A 580, 105 (2013)

[13] E.A. Trofimov, R.Y. Lutfullin, R.M. Kashaev, Lett. Mater. 5, 67 (2015)

[14] K.L. Leary, E. Merson, K. Birmingham, D. Harvey, R. Brydson, Mater. Sci. Eng. A 527, 7694 (2010)

[15] C. Wu, H. Yang, H. Li, Acta Metall. Sin. -Engl. Lett. 26, 5 (2013)

[16] A.A. Antonysamy, J. Meyer, P.B. Prangnell, Mater. Charact. 84, 153 (2013)

[17] A. Fall, H. Monajati, A. Khodabandeh, M.H. Fesharaki, H. Champliaud, M. Jahazi, Mat. Sci. Eng. A 749, 166 (2019)

[18] K. Tirsatine, H. Azzeddine, Y. Huang, T. Baudin, A. Helbert, F. Brisset, D. Bradai, T.G. Langdon, J. Alloy. Compd. 753, 46 (2018)

[19] European, standard. NF EN 15305, April (2009)

[20] B. Mehdi, R. Badji, V. Ji, B. Allili, D. Bradai, F. DeschauxBeaume, F. Soulié, J. Mater. Process. Technol. 231, 441 (2016)

[21] ASTM.E8/E8M-16a Standard test methods for tension testing of metallic materials, ASTM International (2016)

[22] K. Kamlesh, M. Manoj, K.S. Santosh, J. Mat. Proc. Techol. 265, 34 (2019)

[23] N. Kherrouba, D. Carron, M. Bouabdallah, R. Badji, J. Mater. Eng. Perform. 28, 6921 (2019)

[24] Y.T. Lee, G. Welsch, Mat. Sci. Eng. A 128, 77 (1990)

[25] C. Leyens, M. Peters (eds.), Titanium and Titanium Alloys: Fundamentals and Applications (Wiley, Hoboken, 2003)

[26] L.C. Zhang, L.Y. Chen, Adv. Eng. Mater. 21, 1 (2019)

[27] H.J.Y.J. Lee, K.O. Lee, Acta Metall. Sin. -Engl. Lett. 28, 684 (2015)

[28] L. Peng, F. Aihan, Y. Shijian, L. Geping, S. Jun, Mat. Sci. Eng. A. 563, 16 (2013)

[29] N. Gey, M. Humbert, Acta Mater. 50, 277 (2002)

[30] K. Bikash, B. Swarup, Opt. Lasers Eng. 122, 209 (2019)

[31] G.Q. Wang, Z.B. Zhao, B.B. Yu, J.R. Liu, Q.J. Wang, J.H. Zhang, R. Yang, J.W. Li, Acta Metall. Sin. -Engl. Lett. 30, 499 (2017)

[32] K. Topolski, T. Brynk, H. Garbacz, Arch. Civ. Mech. Eng. 16, 927 (2016)

[33] M. Hiroaki, C. Akihiko, H. Shuji, Mat. Sci. Eng. A 486, 503 (2008)

[34] N.S. Biradar, R. Raman, J. Mater. Eng. Perform. 21, 2495 (2012)

[35] M.R. Bache, W.J. Evans, Mat. Sci. Eng. A 319, 409 (2001)

[36] E. Maawad, W. Gan, M. Hofmann, V. Ventzke, S. Riekehr, H.G. Brokmeiera, N. Kashaeva, M. Müller, Mater. Des. 101, 137 (2016)

[37] Y.M. Cui, C.H. Li, C.S. Zhang, R.G. Li, Y. Ren, W.W. Zheng, Y.D. Wang, Mater. Sci. Eng. A 772, 138806 (2020) 